\title{
ESTRUCTURA ORGANIZACIONAL PIRAMIDAL DE LOS ORGANOS JURISDICCIONALES EN EL PERÚ Y EN EL EXTRANJERO
}

\author{
Manuel Jesús Miranda Canales*
}

\begin{abstract}
Resumen:
Este artículo, tiene la finalidad de hacer conocer, muy brevemente, la estructura jurisdiccional piramidal del Perú y algunos países extranjeros como: Argentina, Chile, Bolivia, Brasil, Estados Unidos, España, Italia y Francia haciendo referencia a los órganos de gobierno o de apoyo que conforma el Sistema Judicial en cada uno de estos países.
\end{abstract}

Palabras clave: Estructura Judicial - Sistema Judicial - Corte Suprema Audiencia - Juzgados.

Abstract:

This article explains, very briefly, the pyramidal jurisdictional structure of Peru and some foreign countries like: Argentina, Chile, Bolivia, Brazil, The United States, Spain, Italy and France, making reference to the support or control systems that conforms the Judicial System in each one of these countries.

Key words: Judicial structure - Judicial System - Supreme Court - Hearing - Court Room.

\section{Sumario:}

1. Estructura Jurisdiccional del Perú. 2. Estructura Jurisdiccional de Argentina. 3. Estructura Jerárquica Jurisdiccional de Chile. 4. Estructura Jerárquica Jurisdiccional de Bolivia. 5. Estructura Jerárquica Jurisdiccional de Brasil. 6. Estructura Jerárquica Jurisdiccional de Estados Unidos. 7. Estructura Jerárquica Jurisdiccional de España. 8. Estructura Jerárquica Jurisdiccional de Italia. 9. Estructura Jerárquica Jurisdiccional de Francia.

* Vocal Provisional de la Corte Suprema de Justicia de la República del Perú. Ex Consejero del Consejo Nacional de la Magistratura. 
Manuel Jesús Miranda Canales - Estructura organizacional piramidal de los órganos jurisdiccionales en el Perú y en el extranjero

\section{INTRODUCCIÓN}

El presente artículo, tiene la finalidad de hacer conocer, muy brevemente, la estructura jurisdiccional piramidal denuestro paísy al gunos países extranjeros, haciendo referencia a los órganos de gobierno o de apoyo que conforma el SistemaJudicial.

\section{ESTRUCTURA JURISDICCIONAL DEL PERÚ}

\subsection{SISTEM A JUDICIAL}

El SistemaJudicial Peruano, estáconformado, en lo medular, por el Poder Judicial, el Consejo Nacional de la Magistratura, el Ministerio de Justicia, la Defensoría del Pueblo, el Ministerio Público, el Tribunal Constitucional y otrosorganismos que cumplen funciones vinculadas al ámbito jurisdiccional, como el Instituto Nacional Penitenciario, el Instituto de Medicina Legal y la Policía N acional.

En el Perú, el Poder Judicial tiene como función el ejercicio de la potestad jurisdiccional, o potestad de "administrar justicia", como lo prescribe la actual Constitución (artículo 138으, párrafo 1) ${ }^{1}$, la que comprende, entre otros, los siguientes actos:

- La tutela de los derechos fundamentales.

- La tutela de los derechos ordinarios o intereses legítimos.

- La sanción de los delitos.

- El control dela legalidad dela actuación delas autoridades administrativas.

- El control dela constitucionalidad y la legalidad del ejercicio dela potestad reglamentaria; y

- El control difuso de la constitucional idad de las leyes y normas con rango deLey.

Para un adecuado desarrollo desus actividades jurisdiccionales, gubernativas y administrativas, el Poder Judicial seorganiza en un conjunto decircunscripciones territoriales denominadas distritos judiciales, cada una delas cuales está bajo la dirección y responsabilidad deuna CorteSuperior de Justicia.

En líneas generales, puede decirse que los distritos judiciales suelen coincidir con la demarcación política de los departamentos del país, aunque se observa una particularidad. Así, existen 29 distritos judiciales a nivel nacional, 
Manuel Jesús Miranda Canales - Estructura organizacional piramidal de los órganos jurisdiccionales en el Perú y en el extranjero

destacánd osequeen la capital dela República, operan dos cortes superiores, a saber, la CorteSuperior de Justicia de Lima (la más grandedel país) y la Corte Superior de Justicia de Lima Norte, a las cuales sesuma por su proximidad, la CorteSuperior del Callao.

El rol gubernativo esta relacionado con la "conducción" del Poder Judicial "y consisteen la potestad dedecidir la marcha institucional en sus diversos planos deactividad. Así, las funciones de gobierno judicial, comprenden las siguientes tareas especificas:

- Fijar políticas generales,

- A probar los planes de desarrollo de la institución,

- A probar los presupuestos, asignando los recursos necesarios para al canzar los objetivos de la institución,

- Proyectar el comportamiento futuro dela organización,

- Dictar normas y reglamentos para la administración del propio Poder Judicial,

- Mantener relaciones institucionales con los otros poderes y organismos públicos y privados,

- Establecer mecanismos de comunicación interna y externa,

- Designar autoridades judiciales,

- Seleccionar y designar a los integrantes de la organización; y

- Realizar el control institucional.

Los órganos degobierno del Poder Judicial son el Presidentedel Poder Judicial, La Sala Plena de la Corte Suprema de Justicia, el Consejo Ejecutivo del Poder Judicial, la Oficina de Control de la Magistratura y el Consejo Nacional de la Magistratura, que a pesar de ser un órgano autónomo, tiene atribuciones relevantes para la administración de justicia.

A continuación presentamos cada uno deestos órganos, a excepción del Consejo Nacional dela Magistratura, que será objeto de análisis más adel ante:

Presidentedel Poder Judicial.

Conforme a la Constitución vigente, "el Presidente de la Corte Suprema, lo es también del Poder Judicial" (Artículo 144) y como tal, según prescribe la Ley Orgánica del Poder Judicial, "es el jefe máximo del Poder Judicial y como tal, le corresponde los honores de titular de uno de los poderes del Estado"2 (Artículo 
Manuel Jesús Miranda Canales - Estructura organizacional piramidal de los órganos jurisdiccionales en el Perú y en el extranjero

730, LOPJ). El Presidente dela CorteSuprema de Justicia, del Poder Judicial y del Consejo Ejecutivo del Poder Judicial, es pues, la primera autoridad ejecutiva dela institución.

Es elegido entre los vocales supremos titulares reunidos en Sala Plena, por mayoría absoluta, por un periodo de dos años, mediante votación secreta, hallándose prohibida la reelección.

El Presidente de la Corte Suprema, en la ceremonia de inicio de Año Judicial, dirige un mensajea la nación, en el queda cuenta de la labor jurisdiccional, de las más importantes actividades realizadas, del cumplimiento dela política de desarrollo del Poder Judicial, así como de las mejoras y reformas que estima necesaria efectuar duranteel año queseinicia. También, informa a cerca de los vacíos y deficiencias de las leyes.

Sala Plena de la Corte Suprema

La actual Constitución Política señala que "la Sala Plena de la Corte Suprema, es el órgano máximo dedeliberación del Poder Judicial (Art. 144). En tal sentido, decide sobre la marcha institucional de dicho Poder y sobre todos los asuntos que no sean de competencia exclusiva de otros órganos.

\section{Consejo Ejecutivo del Poder J udicial}

El Consejo Ejecutivo del Poder Judicial "es el tercer órgano de gobierno de la institución y constituye una novedad respecto del antiguo sistema gubernativo, que descansaba solo sobreel Presidente dela CorteSuprema y la Sala Plena del máximo tribunal" ${ }^{3}$. Esteórgano que poseeimportantes atribuciones dedirección dela entidad, tieneuna composición plural, en laque participan magistrados de diversos gradosy un representantedel Gremio delosA bogados (Sociedad Civil).

Entre sus atribuciones, destacan:

Proponer a la Sala Plena de la Corte Suprema la política general del Poder Judicial y aprobar el Plan de Desarrollo del mismo, determinar el número de Salas Especializadas Permanentes, y excepcionalmente, el número de Salas Transitorias dela CorteSuprema.

A probar el Proyecto dePresupuesto del Poder Judicial, propuesto por la Gerencia General y ejecutarlo una vez sancionado legalmente; y resolver, en última 
Manuel Jesús Miranda Canales - Estructura organizacional piramidal de los órganos jurisdiccionales en el Perú y en el extranjero

instancia, las medidas deapercibimiento, multa y suspensión impuestas por la Oficina deControl dela Magistratura, en contra de los magistrados.

El mandato de los integrantes del Consejo Ejecutivo del Poder Judicial tiene una duración de dos años.

Oficina deControl dela M agistratura

La Oficina de Control de la Magistratura (OCMA), tiene a su cargo "la función disciplinaria al interior del aparato de administración de justicia y ejerce atribuciones tanto sobre los jueces como sobre los auxiliares de justicia". En tal sentido, la Ley Orgánica del Poder Judicial estipula que la OCMA "es el órgano quetiene por función investigar regularmentela conducta funcional, la idoneidad y el desempeño delos magistrad os y auxiliares jurisdiccionales del Poder Judicial", facultad que sin embargo "no excluye la evaluación permanente que deben ejercer los órganos jurisdiccionales al conocer los proceso en grado" 4 .

La OCM A, es dirigida por un vocal supremo designado por la Sala Plena dela Corte Suprema de Justicia. La integran vocales superiores y Jueces especializados o mixtos, a dedicación exclusiva, en el número determinado por el Consejo Ejecutivo del Poder Judicial, que los nombra por un período improrrogabledetres años.

\subsection{ESTRUCTURA JERÁRQUICA JURISDICCIONAL}

En el desarrollo de su labor jurisdiccional, el Poder Judicial poseela siguiente estructura jerárquica:

- La CorteSuprema dejusticia

- Las Cortes Superiores de Justicia

- Los juzgados Especializados y Mixtos

- LosJuzgado Paz Letrados

- LosJuzgados dePaz

Corte Suprema de Justicia

La Constitución actual señala que "corresponde a la Corte Suprema fallar en casación, o en última instancia, cuando la acción seinicia en una Corte Superior o ante la propia Corte Suprema conforme a Ley", agregando que "asimismo 
Manuel Jesús Miranda Canales - Estructura organizacional piramidal de los órganos jurisdiccionales en el Perú y en el extranjero

conoce en casación las resoluciones del Fuero Militar, con las limitaciones que establece el artículo $173^{\circ \prime \prime 5}$, el cual se refiere a los muy excepcional es supuestos deimposición depena demuerte.

Las funciones casatorias dela CorteSuprema, están relacionadas con el control que debe ejercer el máximo tribunal dejusticia sobrela correcta aplicación y la correcta interpretación de una norma de derecho material y el respeto a las garantías deun debido proceso y a las formas esenciales delos actos procesales por los juzgados y tribunales inferiores, así como con la labor de unificación jurisprudencial (sentencias uniformes y reiteradas) queel principio deigual dad ante la ley y el principio de seguridad Jurídica, exigen al Poder Judicial. Por contraste, la intervención jurisdiccional como "ultima instancia" importa que la Corte Suprema, expida sentencias sobre el fondo de las controversias, resolviéndolas demanera definitiva.

La Corte Suprema de Justicia, que tiene su sede en la capital de la República, extiendesu competenciajurisdiccional a todo el territorio nacional, y es el más alto tribunal de la judicatura ordinaria del país. Para su trabajo resolutorio de conflictos, se divide en salas especializadas permanentes y transitorias. Cada sala está integrada por cinco vocales y es presidida por quien designe el Presidente de la Corte Suprema. Las especialidades son tres: deDerecho Civil, deDerecho Penal y deDerecho Constitucional y Social. En la actualidad, existen tres salas permanentes y cuatro Salas Transitorias Supremas.

\section{Cortes Superiores deJ usticia}

Las Cortes Superiores de Justicia extienden su competencia jurisdiccional al interior desu respectivo distrito judicial, cada una deellas, cuenta con las salas especializadas o mixtas que señala el Consejo Ejecutivo del Poder Judicial, según las necesidades del correspondiente distrito.

Las Salas Superiores pueden funcionar en una ciudad o provincia distinta de la sededela CorteSuperior. Cada Sala está integrada por tres vocal es superiores y es presidida por el de mayor antigüedad. Conforme a la Ley Orgánica del Poder Judicial; Iassal as de las Cortes Superiores resuelven en segunda y última instancia, con las excepciones que establece la Ley. Si la Corte Superior, tiene más de una sala de la misma especialidad, los procesos han de ingresar por turnos quefija el Consejo Ejecutivo Distrital. 
Manuel Jesús Miranda Canales - Estructura organizacional piramidal de los órganos jurisdiccionales en el Perú y en el extranjero

Juzgados Especializados y M ixtos

Los Juzgados Especializados y Mixtos, cuya sedees la capital dela provincia y, a veces, la capital dedistrito, tienen las siguientes especialidades: civil, penal, de trabajo, de familia, contencioso administrativo y comercial. Allí donde no haya Juzgados Especializados, el Despacho debeser atendido por un Juzgado Mixto, con la competencia que ha de establecer el Consejo Ejecutivo del Poder Judicial. Todos los Juzgados - Especializados y Mixtos- tienen la misma jerarquía.

Juzgados de Paz Letrados

Los Juzgados dePaz Letrados extienden su competenciajurisdiccional al ámbito queestableceel Consejo Ejecutivo del Poder Judicial. Esteúltimo, creal losJuzgados de Paz Letrados, considerando los volúmenes demográficos, rurales y urbanos delos distritos, y señala los requisitos que deben cumplirse para tal creación.

En estos Juzgados sesustancian las causas demenor cuantía quela ley determina o derápida solución. Resuelven además, las apelaciones delosJuzgados dePaz.

Correspondeal Consejo Ejecutivo Distrital, fijar el sistema de distribución de los procesos entre los Juzgados de Paz Letrados cuando sea necesario.

También, puede disponer su especialización, si ello conviene a la mejor administración de justicia y lo amerita la carga procesal.

En los lugares dondehay un Juzgado dePaz Letrado, no puedehaber un Juzgado dePaz; aquel debe asumir la competencia en las acciones y los asuntos propios de éste, para lo que aplica las normas de procedimiento correspondientes a la Justicia de Paz. Tanto las resoluciones de los Juzgados de Paz Letrados como delosJuzgados dePaz, son conocidasen grado deapelación por los respectivos Juzgados Especializados o Mixtos.

Juzgados de Paz

Les corresponde a éstos, investigar y sancionar casos de faltas menores y funcionan en los pueblos, caseríos y distritos pequeños donde no hay mucho movimiento judicial. Para que desempeñeestecargo, el mismo pueblo eligea una persona deprestigio, probidad y honestidad, queno necesariamenteseráabogado. LosJueces dePaz, dependen dela CorteSuperior queratifica su nombramiento. 
Manuel Jesús Miranda Canales - Estructura organizacional piramidal de los órganos jurisdiccionales en el Perú y en el extranjero

Los Jueces de Paz, que en al actualidad suman al rededor de 5,000, son mucho mas numerosos que los magistrad os formales y, empleando su propio criterio de justicia -dado que no están obligados a fallar de acuerdo con la ley- logran resolver millares de casos al año.

La Justicia de Paz, se mantiene especial mente en las zonas rurales y las dos terceras partes delos Jueces dePaz, se, encuentran en la región andina. El resto sedivide, en una proporción similar, entrela costay la región amazónica. Estas diferencias son muy importantes, por cuanto la Justicia de Paz" reproduce, en si misma, la heterogeneidad y las diferencias culturales presentes entre los peruanos. Deestaforma, tenemos quelos Jueces de Paz dela sierra suelen vivir bajo un marcado aislamiento. Muchos de ellos tiene un nivel educativo muy bajo y resuelven el conflicto en el idioma de las partes, quechua o aimara. Es notable el contraste con muchos Jueces de Paz de la costa, quienes tienen educación superior y un contacto mas cercano con las leyes y el Poder Judicial.

Cabe señalar que los Jueces de Paz son esencialmente conciliadores, están facultados para proponer alternativas de solución a las partes con el fin de facilitar el avenimiento. Correlativamente, les está prohi bido imponer soluciones bajo la apariencia de acuerdos voluntarios. No obstante, si no se logra la conciliación, los Jueces de Paz, están legalmente habilitados para expedir sentencias, en los procesos desu competencia y dentro dela cuantía queestablece el Consejo Ejecutivo ${ }^{6}$. De cualquier modo, "existe impedimento legal expreso para quelaJ usticia dePaz intervenga bajo la modalidad conciliatoria o defallo, en determinados asuntos, que por su importancia o complejidad exige el concurso de la justicia profesional. Tales asuntos son los relativos al vínculo matrimonial, de nulidad y anulabilidad de actos jurídicos o contratos, la declaratoria deherederos, los derechos sucesorios, los testamentos, los derechos constitucionales y aquel los que expresamente señala la ley.

Conforme a la LOPJ, la competencia jurisdiccional de los Juzgados de Paz "que los habilita para emitir sentencias en caso de fracasar la conciliación", es la siguiente:

- Alimentos, siempre que el vinculo de entroncamiento esté acreditado de manera indubitable.

- Desalojo y aviso de despedida.

- Pago dedinero.

- Interdictos deretener y derecobrar respecto de bienes muebles. 
Manuel Jesús Miranda Canales - Estructura organizacional piramidal de los órganos jurisdiccionales en el Perú y en el extranjero

- Intervenciones sumarias respecto de menores que han cometido acto antisocial y con el solo objeto de dictar ordenes provisionales y urgentes sobre tenencia o guarda del menor en situación de abandono o peligro moral, concluida su intervención, el Juez de Paz remite de inmediato lo actuado al Juez de Familia o al Juez que corresponda; y

- Los demás casos que correspondan conformea Ley

\section{ESTRUCTURA JURISDICCIONAL DEARGENTINA}

\subsection{SISTEM A JUDICIAL}

Según lo establece la Constitución Nacional, Argentina adopta para su gobierno la forma representativa, republicana y federal ${ }^{8}$. La Constitución estableció el gobierno federal, con sus tres poderes, Ejecutivo, Legislativo y Judicial, y reconoció la existencia de los gobiernos provinciales, los cuales retienen todo el poder no delegado a la N ación. En base a estas facultades no delegadas, cada provincia debe dictar su propia constitución de acuerdo a los principios, declaraciones y garantías de la Constitución Nacional; asegurando la administración dejusticia, el régimen municipal, y la educación primaria.

El sistemajudicial argentino, está compuesto por el Poder Judicial delaNación, el Ministerio Público de la Nación, ambos instituidos por la Constitución Nacional y por los poderes judiciales delas provincias, y delaCiudad A utónoma deBuenos Aires, y en el ámbito del Poder Ejecutivo, seincluyeal Ministerio de Justicia de la Nación, el Servicio Penitenciario Federal y la Policía Federal.

El sistema judicial argentino, está basado en la tradición europea continental dederecho codificado. Los procedimientosjudiciales son mayormenteescritos, la excepción a esto se da principal mente en los procesos penales, en la etapa de juzgamiento donde se realizan debates orales. No obstante existen provincias que aún no han implementado la oralización para las causas penales.

Para dimensionar este sistema se puede entonces sumar a lo ministerios de justicia u organismos análogos dentro de la órbita de los poderes ejecutivos, y en los caso en que exista, los servicios penitenciarios y policía judicial (o de investigación si la hubiera). Por otra parteno debemos olvidar el fundamental rol quecumplen los abogados, ya sea a través del ejercicio profesional como así también el despliegue corporativo que real izan los colegios deabogados. 
Manuel Jesús Miranda Canales - Estructura organizacional piramidal de los órganos jurisdiccionales en el Perú y en el extranjero

\section{Organigrama deSistemaJ udicial Federal}

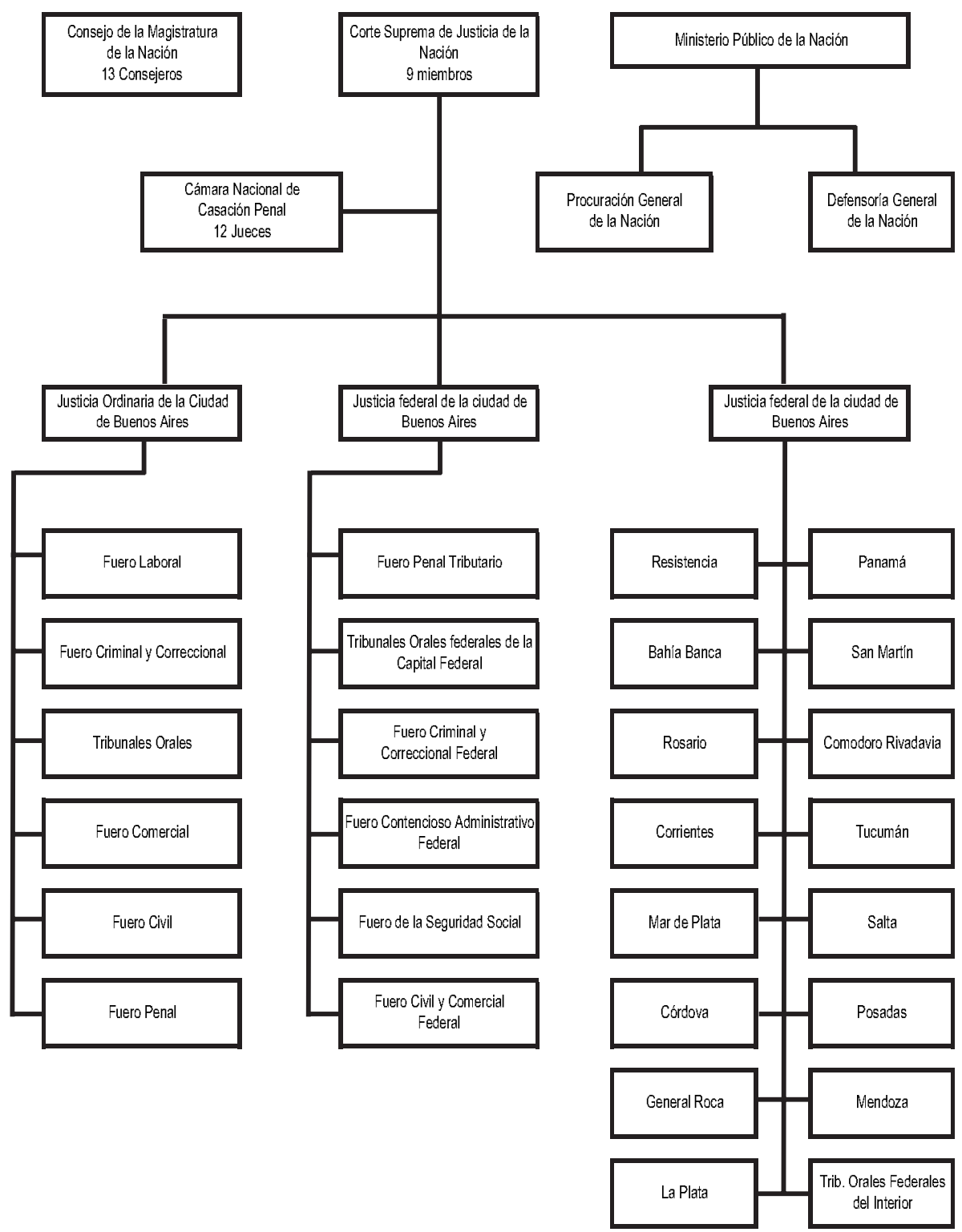


Manuel Jesús Miranda Canales - Estructura organizacional piramidal de los órganos jurisdiccionales en el Perú y en el extranjero

\section{Organización}

El Poder Judicial de la Nación, está compuesto por la Corte Suprema de Justicia dela Nación, las Cámaras de A pelaciones y los Juzgados dePrimera Instancia.

La estructura del Poder Judicial de Ia Nación, está dividida en tres jurisdicciones:

1. La jurisdicción federal, que incluye aquel los tribunales con competencia para conocer sobre asuntos federal es en todo el territorio del país.

2. Lajurisdicción federal dela Capital Federal, queincluyeaquellos tribunales con competencia para conocer sobre asuntos federales en el territorio dela Capital Federal.

3. La jurisdicción ordinaria de la Capital Federal que incluye aquellos tribunales con competencia para conocer sobre asuntos de derecho común en el territorio dela Capital Federal.

Corte Suprema de Justicia de la Nación

Organización y Composición

LaCorteSuprema de Justicia dela Nación, es el Órgano Supremo y máximo del Poder Judicial, está compuesta por 9 miembros ejerce su jurisdicción en todos aquellos puntos regidos por la Constitución y las leyes de la Nación ${ }^{9}$; pero, ejercesu competencia en forma originaria y exclusiva en todos los asuntosque conciernen a los embajadores, ministros y cónsules extranjeros, y en los que alguna provincia fueses parte ${ }^{10}$. La Corte Suprema es también la cabeza del Poder Judicial, y conjuntamente con el Consejo de la Magistratura) tiene a su cargo la administración del Poder Judicial.

El Presidente de la CorteSuprema de Justicia, es elegido por sus pares. Todos los miembros de la CorteSuprema son designados por el Poder Ejecutivo con acuerdo del Senado y a partir dela vigencia del Decreto número 222 del 19 de junio del 2003 se incorpora un requisito más en el procedimiento para la designación delosmiembros del Superior Tribunal dela Nación, quees la dela publicación previa en los antecedentes curriculares de los candidatos con el objeto que los ciudadanos en general, las organizaciones no gubernamentales, los colegios y asociaciones profesionales) presenten anteel Ministerio deJusticia 
Manuel Jesús Miranda Canales - Estructura organizacional piramidal de los órganos jurisdiccionales en el Perú y en el extranjero

y Derechos Humanos de la Nación sus observaciones y consideraciones que crean de interés expresar sobreel candidato propuesto por el Poder Ejecutivo.

Dentro del Poder Judicial de la Nación, hay distintos fueros, los cuales se encuentran separados unos de otros. Cada uno de estos fueros se componen por una Cámara de A pelaciones y los respectivos Juzgados de Primera Instancia. A su vez, estosfueros, están subdivididos en lajurisdicción Federal y la Ordinaria. La jurisdicción Ordinaria maneja los asuntos judiciales comunes de la Ciudad de Buenos Aires, y esta compuesta, además, por la Cámara Nacional de A pelaciones en lo Civil, Ia Cámara Nacional de A pelaciones en lo Criminal, Ia Cámara Nacional de A pelaciones en Io Comercial y la Cámara Nacional deA pelaciones del Trabajo. La Jurisdicción Federal, esta separada por las Cámaras Federales del Interior del país. Los siguientes fueros tienen asientos en la ciudad de Buenos Aires: Cámara Criminal y Correccional Federal, Cámara Civil y Comercial federal, Cámara Contencioso A dministrativo Federal. Cámara dela Seguridad Social Federal. En el interior del país, las Cámaras Federal es no están separadas por fueros, sino que juzgan causas de todas las materias.

\section{ESTRUCTURA JerárquicaJURISDICCIONAL DE CHILE ${ }^{11}$}

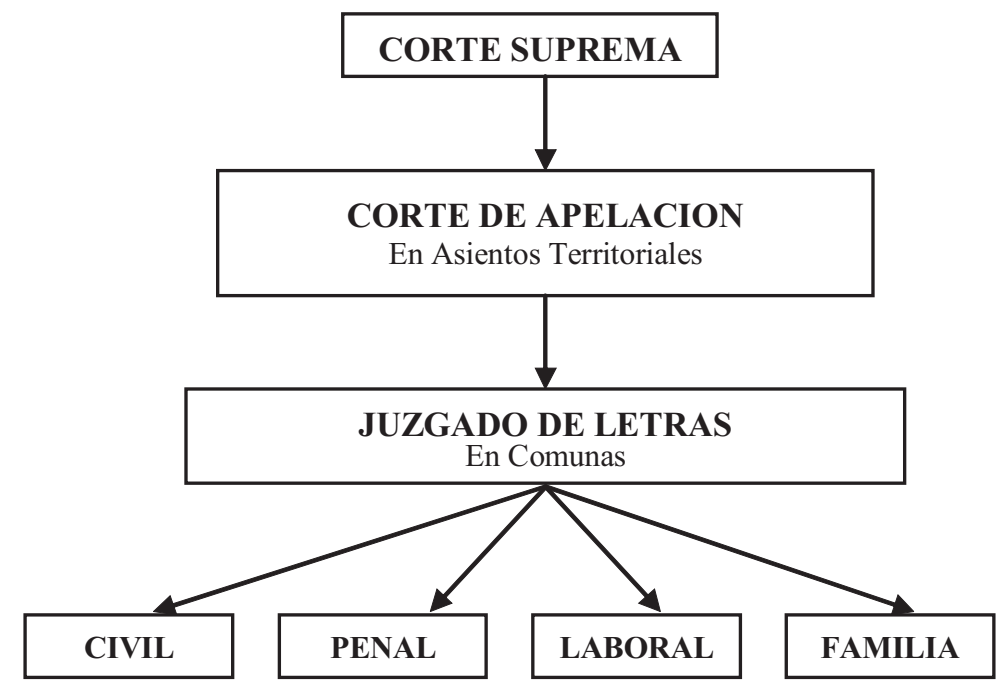




\section{ESTRUCTURA JerárquicaJURISDICCIONAL DE BOLIVIA ${ }^{12}$}

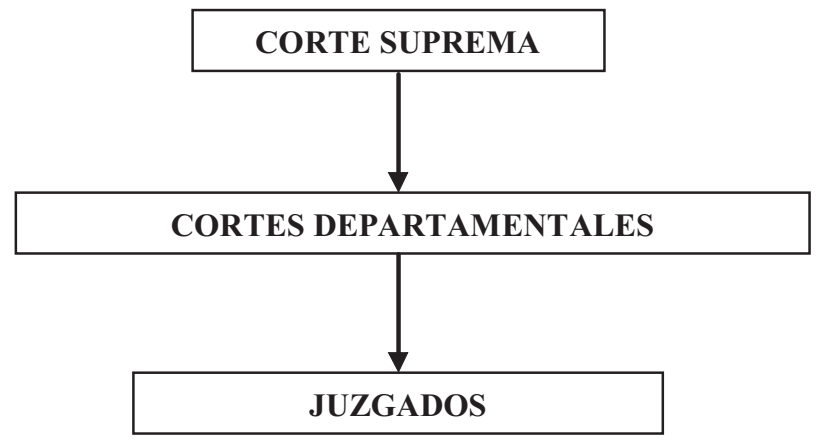

5. ESTRUCTURA JerárquicaJURISDICCIONAL DE BRASIL

\subsection{SISTEM A JUDICIAL}

El sistema dejusticia en Brasil, siguela tradición europea continental de derecho escrito. Estáintegrada por el Poder judicial, el Ministerio Publico, el Ministerio deJusticia y las Fuerzas de Seguridad.

PoderJudicial

El Sistema Judicial brasileño posee una organización federal y una estatal.

A nivel federal, el Poder judicial sedivideen 5 regiones. Los órganos demayor jerarquía son: el Supremo Tribunal Federal y los Tribunales Superiores, que ejercen su jurisdicción sobre todo el territorio de la República. Además, cada una de las 5 regiones judiciales posee un Tribunal Regional Federal, el que conoce, principalmente, los recursos de apelaciones. Por último, cada región judicial sedivideen un número variablede secciones judiciales, Ias que poseen juzgados de primera instancia en todas las materias. La jurisdicción laboral cuenta con características propias: esta divida en 24 regiones judiciales, cada una de las cuales tiene su propio Tribunal Regional del Trabajo.

Los Tribunales Regionales del Trabajo conocen los recursos ordinarios que se interponen en contra de las decisiones de los juzgados del trabajo. Además, deben resolver los conflictos colectivos surgidos entre asociaciones de trabajadores y su empleador o empleadores. Hay 24Tribunales Regionales del Trabajo. 
Manuel Jesús Miranda Canales - Estructura organizacional piramidal de los órganos jurisdiccionales en el Perú y en el extranjero

El Tribunal Superior del Trabajo -cuya sede se halla en Brasilia-DF- posee jurisdicción en todo el territorio nacional y su principal función es uniformar la jurisprudencia en materia laboral.

En esta línea le corresponde juzgar los recursos interpuestos contra las decisiones de los Tribunal es Regionales. El Tribunal Superior del Trabajo esta integrado por 17 ministros.

Tribunales y Jueces Estaduales.

La Constitución Federal delega a los Estados, la competencia de organizar su propia justicia y competencias definidas en la Constitución del Estado. La Justicia Estadual comprendeun Tribunal deJusticia por Estado, con capacidad para revisar las decisiones de los Tribunales de Primera Instancia Estadual, entre otras. La Constitución Federal prevéla posibilidad a losEstados decrear su propia Justicia Militar Estadual, con competencia para procesar y juzgar a los policías militares y bomberos militares en los crímenes definidos en la ley.

LaJusticia estadual comprende, también, los Juzgados Especiales Estaduales, formados por jueces o jueces y legos, idóneos para la conciliación y juzgamiento de causas civiles de menor cuantía e infracciones penales menores, mediante procedimiento sumarísimo.

6. ESTRUCTURA Jerárquica JURISDICCIONAL DE ESTADOS UNIDOS SISTEMAJUDICIAL

\subsection{PODERJUDICIAL FEDERAL}

LaJudicatura Federal fueestablecida por el Artículo III dela Constitución y es uno de tres poderes iguales, pero distintivos del Gobierno Federal. Tiene la misión de aplicar e interpretar las leyes y resolver disputas. Dicho artículo prescribe: "El Poder Judicial de los Estados Unidos será confiado a una Corte Suprema y a los Tribunales menores, cuya formación sea ordenada por el Congreso en distintas oportunidades ${ }^{134}$.

Visto como una pirámi de, el sistema decortes federales esta encabezado por la CorteSuprema de los Estados Unidos. En el próximo nivel están las 13 Cortes deA pelaciones correspondientes a los Circuitos Judiciales y, en la base, las 94 Cortes deDistrito y las Cortes Especializadas. 
Manuel Jesús Miranda Canales - Estructura organizacional piramidal de los órganos jurisdiccionales en el Perú y en el extranjero

La Judicatura Federal, de acuerdo con lo establecido en el Artículo III de la Constitución, tiene jurisdicción sobre controversias que surjan de asuntos federales y jurisdicción sobre "diversidad de ciudadanía". Las Cortes Federales deciden casos que involucran al Gobierno de Estados Unidos, Ia Constitución, actos del Congreso y tratados, o controversias entre Estados o entre Estados Unidos y un gobierno de otro país. También tiene jurisdicción en las controversias entre ciudadanos de distintos Estados.

Las Cortes federales y estatales tienen jurisdicción simultánea - o en el mismo período - sobre ciertos asuntos como crímenes asociados a drogas. Esto significa quelos litigantes pueden escoger entre una cortefederal o una social. Algunos asuntos legales sol o pueden ser conocidos en una cortefederal o en una estatal. Los casos dequiebra y relacionados con el derecho marítimo, por ejemplo, son decompetencia delas cortes federales.

\section{CorteSuprema delos Estados Unidos}

Esla CortedeA pelaciones demayor importancia en el país y la corte deúltimo recurso para apelaciones de casos conocidos en otras cortes federales y estatales. Está integrado por nuevemiembros conocidos como J ustices, nombrados por el Presidente deEE.UU., con la aprobación del Senado.

El Presidente de la Corte Suprema tiene deberes administrativos adicionales relacionados a la CorteSupremay al sistema de cortes federales en su totalidad. Los otros ocho miembros dela Corteson conocidos como A ssociate Justices.

La Corte Suprema posee jurisdicción original en disputas entre dos o más Estados y en casos donde al gunas de las partes son embajadores o ministros.

También actúa como Tribunal deA pelaciones, para revisar casos delas cortes de circuito federal y las cortes estatales de último recurso.

La Corte decide, más o menos 100 de los 5,000 o más casos queson presentados para revisión cada año. Normalmente solo acepta los casos que involucran importantes interpretaciones dela Constitución, actos de órganos legislativos y tratados.

La mayoría desus decisiones se dan a conocer en opiniones públicas. Algunos de los aspectos que la Corte considera para revisar un caso: 
Manuel Jesús Miranda Canales - Estructura organizacional piramidal de los órganos jurisdiccionales en el Perú y en el extranjero

- Si dos cortes federales de apelaciones han llegado a distintas conclusiones con respecto a un solo tema legal.

- Si una corte federal de apelaciones ha decidido un tema federal de una forma queentra en conflicto con la decisión de una cortedeúltimo recurso (La CorteSuperior en el Estado).

- Si una corte federal de apelaciones ha ido más allá de los procedimientos judiciales aceptados, o ha sancionado ese tipo de acción por parte de una cortemenor.

- Si una cortedeúltimo recurso ha decidido un caso federal deuna formaque entraen conflicto con la decisión dela cortedeúltimo recurso deotro Estado o de una cortefederal de apelaciones; y

- Si una corteestatal o cortefederal deapelaciones ha decidido un importante tema de ley federal de una forma que entre en conflicto con anteriores decisiones de la Corte Suprema, a un tema de ley federal que no ha sido, pero debería deser decidido por la CorteSuprema.

\section{ESTRUCTURA JERÁRQUICA JURISDICCIONAL DE ESPAÑA}

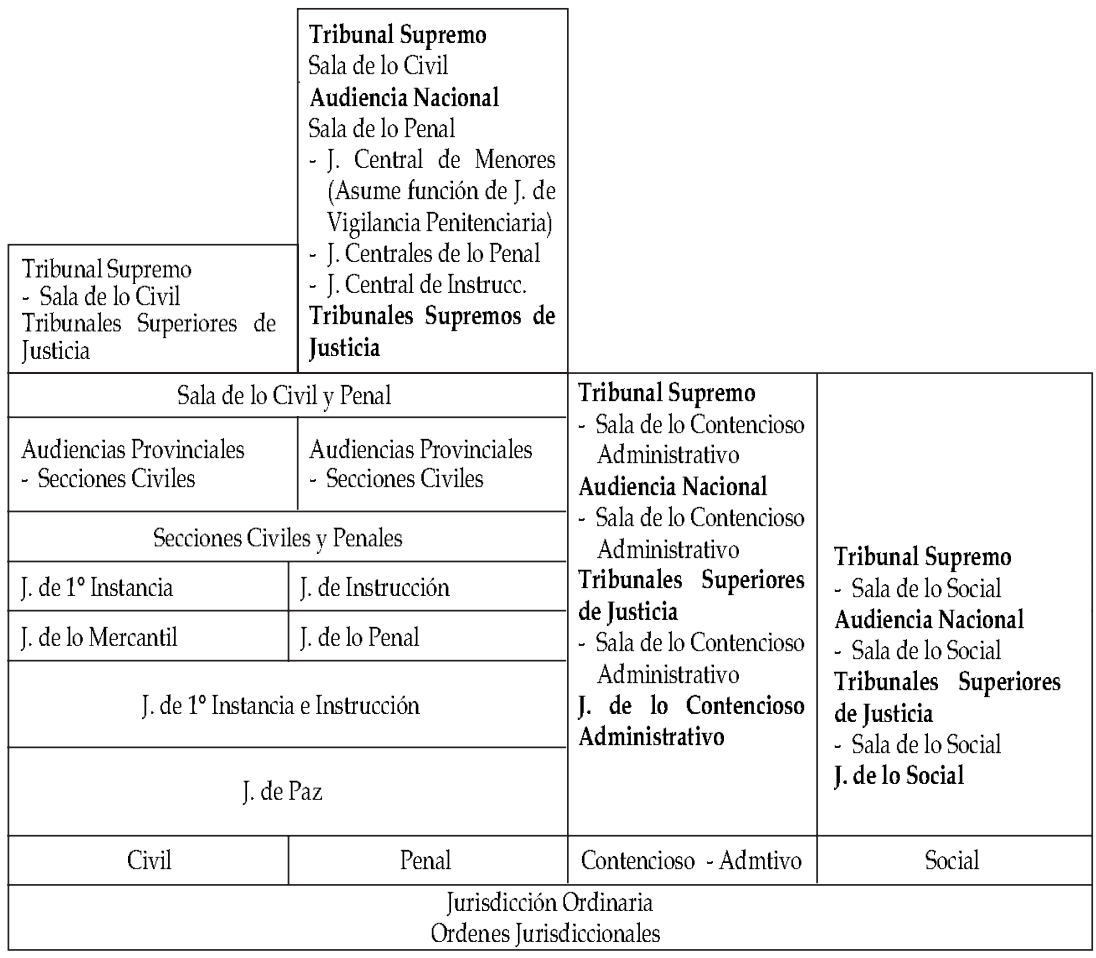


Tribunal es Superiores de Justicia

Representan la innovación más importante en la estructura judicial española quees una consecuencia del Estado delas A utonomías, ya quecon ellos, culminará la organización judicial en el ámbito territorial dela Comunidad Autónoma, sin perjuicio delajurisdicción quecorrespondeal Tribunal Supremo. Los Tribunales Superiores de Justicia están integrados por las Salas de lo Civil y Penal, de lo Contencioso - Administrativo y delo Social Art. 720L.O.P.J.).

\section{Audiencia Nacional}

Con su sedeen Madrid, tienejurisdicción en toda España. Consta detres Salas: Sala de lo Penal (deúnica instancia para los delitos más graves previstos en el artículo 650 de la Ley Orgánica del Poder Judicial), Sala de lo Contencioso Administrativo y Sala de lo Social.

\section{Audiencias Provincial es}

Tendrán su sede en la capital de la provincia, de la que tomarán su nombre y sobre la que extenderán su jurisdicción, pudiendo crearse secciones fuera de la capital dela provincia, a laquequedarán adscritos uno o varios partidos judidiales. Son órganos mixtos ya quetienen competencias en materia penal y civil.

A utonomía de acuerdo con las exigencias de trabajo

Les correspondeel ejercicio de las funciones queestablezcan las leyes paracon los menores que hubieren incurrido en conductas tipificadas por la ley como delito o fal ta y aquel las otras que, en relación con los menores, les atribuyan las leyes.

\section{Juzgados de Menores}

Su ámbito territorial es la provincia, aunque es posible establecerlos con jurisdicción sobre un partido determinado o agrupación de partidos o sobre dos o más provincias de una Comunidad.

Juzgados de Vigilancia Penitenciaria

En cada provincia, y dentro del orden jurisdiccional penal, habrá uno o varios 
Manuel Jesús Miranda Canales - Estructura organizacional piramidal de los órganos jurisdiccionales en el Perú y en el extranjero

Juzgados de Vigilancia Penitenciaria, que tendrán funciones jurisdiccionales previstas en la Ley General Penitenciaria, en materia de ejecución de penas privativas de libertad, medidas de seguridad, control jurisdiccional de la potestad disciplinaria de las autoridades administrativas, amparo de los derechos y beneficios de los internos en los establecimientos penitenciarios y demás queseñalela ley.

Juzgados de lo Contencioso-Administrativo

Son órganos deinstancia con competencia objetiva para conocer del os recursos que se deduzcan contra actos y disposiciones de determinados órganos administrativos. Su demarcación judicial es la Provincia.

Juzgados delo Social

Su ámbito territorial es la provincia, si bien podrán establecerse en poblaciones distintas de la capital cuando las necesidades del servicio o la proximidad a determinados núcleos detrabajo lo aconsejen. Excepcionalmentepodrán extender su competencia a doso más provincias dentro dela misma Comunidad Autónoma. Conocerán en primera o única instancia de los procesos sobre materias propias de este orden jurisdiccional queno están atribuidas a otros órganos del mismo.

Juzgados de lo Penal

De ámbito provincial tienen competencias en el ámbito penal. Fundamentalmente les corresponde el enjuiciamiento de los delitos menos graves. Al Juzgado Central de lo Penal, con sede en Madrid y jurisdicción en toda España, le corresponde el enjuiciamiento de aquellos delitos que por su natural eza se leatribuyen a la A udiencia $N$ acional, pero que por su pena están dentro de los limites de los atribuidos a los Juzgados de lo Penal.

\section{ESTRUCTURA JERÁRQUICA JURISDICCIONAL DEITALIA.}

\subsection{Estructurajerárquicajurisdiccional}

Actualmente la justicia, en las materia civil y penal es administrada por el Juez de Paz, El Tribunal, el Tribunal de A pelación, el Tribunal Supremo de Casación, el Tribunal de Menores, el Magistrado deVigilancia y el Tribunal de Vigilancia. 
Manuel Jesús Miranda Canales - Estructura organizacional piramidal de los órganos jurisdiccionales en el Perú y en el extranjero

Con la reforma sobre el Juez único de Primera Instancia, se ha procedido a la reestructuración delos departamentosjudicial es de Primera Instancia, mediante la supresión del Departamento del "Pretore" (Juez de Primera Instancia para causas menores) y las competencias correspondientes han sido transferidas al tribunal, queahora tieneuna composición monocrítica para losasuntos menores y una composición colegial para los demayor complejidad; dela misma manera, se ha el iminado el Departamento del Fiscal ante el Juzgado de Distrito y sus funciones han sido transferidas al Fiscal ante el Tribunal.

En la misma perspectiva, los magistrados honorarios en servicio anteel órgano eliminado (Prefectura-Juzgado de Primera Instancia) han cambiado su denominación deVice Juez Honorario aJuez Honorario del Tribunal.

\section{Las J urisdicciones Especiales}

La Constitución prohíbe la institución de nuevos jueces "ordinarios o especiales", permitiendo, en el ámbito de la jurisdicción ordinaria, la creación de secciones especializadas en determinados sectores, caracterizadas por la co-presencia, en el mismo órgano que juzga, de magistrados ordinarios y de ciudadanos idóneos pero ajenos al ordenamiento jurídico (por ejemplo, las secciones especializadas agrarias) (Art. 102을 Constitución) ${ }^{14}$.

De todos modos, están previstos jueces especiales, como los jueces administrativos, el Tribunal deCuentas y el Juez Militar, ya existentesa entrada en vigor dela Constitución (Art. 103을 Constitución) ${ }^{15}$.

El Tribunal de Cuentas está compuesto por magistrados contables y, ante el mismo, está constituida una Fiscalía General a la quesehan atribuido funciones requerientes. Recientemente, la Magistratura Contable ha sido reformada estableciendo secciones autónomas jurisdiccionales y requerientes sobre base regional.

El órgano de gobierno autónomo es el Consejo de Presidencia del mismo Tribunal.

Además de la competencia en materia de control previo de legitimidad sobre numerosos actos del Gobierno y de otros organismos públicos, y de control posterior sobre la gestión del presupuesto y del patrimonio de las administraciones públicas, al Tribunal de Cuentas se han atribuido los juicios 
Manuel Jesús Miranda Canales - Estructura organizacional piramidal de los órganos jurisdiccionales en el Perú y en el extranjero

en materia de contabilidad pública, de pensiones y de responsabilidad de los empleados y funcionarios del Estado o de otros entes públicos.

Los Jueces Militares, a los quees atribuida la competencia dejuzgar los delitos militares cometid os por quienes pertenecen a las fuerzas armadas, constituyen un orden de la Magistratura Ordinaria y es administrado por un órgano de gobierno autónomo, el Consejo Superior dela Magistratura General .

Lajurisdicción administrativa es atribuida a un conjunto deentes, distintos de la magistratura ordinaria: Ios Tribunales Administrativos Regionales, como Jueces de Primera Instancia, y el Consejo de Estado, como Juez de Segunda Instancia.

\section{ESTRUCTURA JERÁRQUICA JURISDICCIONAL DE FRANCIA}

\subsection{Estructura jerárquicajurisdiccional}

Su arquitectura es piramidal

Las jurisdicciones de bases.

- En primer lugar están los tribunalesformados por magistrados profesionales. Son tribunales dederecho común de primer grado, quecelebran sus sesiones con el único magistrado, o de forma colegiada con tres miembros, y los tribunales de instancia que siempre cel ebran sus sesiones con un solo magistrado. A mbos tienen competencia en todas las materias que no corresponden de manera especifica a cualquiera de las jurisdicciones especiales quese citan más adelante. La distribución decompetencias entre ambos tribunales seefectúa principal menteen función dela importancia del litigio deque setrate. Algunos jueces están especial izados en determinados asuntos (derecho familiar, expropiación, ejecución desentencias) .

- A continuación, seencuentran los tribunales formados por magistrados no profesionales, el egidos por los grupos social es profesionales afectados por la clase de asuntos quese juzgan en esas jurisdicciones, son los tribunales mercantiles, competentes para los litigios comerciales, y el juzgado de lo social o magistratura del trabajo, competenteen derecho laboral, quees un órgano paritario formado por representantes de patronos y trabajadores. En caso de que se produzca una igualdad de dichos representantes, un 
Manuel Jesús Miranda Canales - Estructura organizacional piramidal de los órganos jurisdiccionales en el Perú y en el extranjero

magistrado profesional presidiría el tribunal. En un proyecto de ley que aún estáen fase de debate, se establecequela presidencia de determinadas audiencias del Tribunal Mercantil serealice por un magistrado profesional, por ejemplo, en el caso delos procedimientos concursales.

- Con respecto al tribunal de derecho común de primer grado, el juez profesional a veces recibe el apoyo de dos magistrados asesores que han sido elegidos en función de sus competencias. Ese es el caso del Tribuna! de Menores, que puede contar con dos personas especializadas en este ámbito; del tri bunal paritario dearrendamientos rústicos, con un propietario y un arrendatario; y por último, del tribunal deasuntos sociales, con asesores para los asuntos relacionados con la seguridad social.

- Sól o existeuna jurisdicción que cuentecon la figura del Jurado. Setrata del Tribunal de lo Criminal, encargado dejuzgar las infracciones más graves, los delitos. Las sesiones de este tribunal se celebran con tres magistrados profesionalesy un jurado compuesto por nuevemiembros (queson doceen el caso del Tribunal deA pelación), que debaten tanto sobre a culpabilidad como sobrela pena a imponer.

Las J urisdicciones de A pel ación

Los Tribunales deA pelación, están formados exclusivamentepor magistrados profesionales, son de tipo regional y entienden de los recursos presentados contra toda clase de resoluciones judiciales dictadas por las jurisdicciones de base (excepción hecha de los litigios de poca importancia que se pueden llevar directamente del Tribunal deCasación). Al igual quelas jurisdicciones de base, Ios tribunales de apelación resuelven sobre los hechos y el derecho, pero únicamentehasta dondelleguen sus competencias, quelas partes pueden haber limitado a determinados puntos del litigio únicamente.

\section{Las J urisdicciones son competencias obj etivas específicas}

A reserva de las disposiciones relativas al Tribunal Penal Internacional, el Presidente de la República solo puede ser juzgado por casos de alta traición, competencia que recaería en la Suprema Corte de Justicia, formada por parlamentarios, y mediantedecisión deambas cámaras legislativas, la Asamblea Nacional y el Senado. El Tribunal de Justicia dela república es responsable de juzgar a los miembros del gobierno respecto a las infracciones que hayan 
Manuel Jesús Miranda Canales - Estructura organizacional piramidal de los órganos jurisdiccionales en el Perú y en el extranjero

cometido durante el ejercicio de sus funciones. Dicho Tribunal está formado por tres magistrados del Tribunal de Casación y por parlamentarios. Las diligencias fiscal es efectuadas por el Fiscal del Tribunal deCasación deben ser autorizadas previamentepor una comisión deadmisión de recursos, compuesta por Magistrados del Consejo deEstado, del Tribunal decasación y del Tribunal deCuentas. Tres magistrados del Tribunal deCasación seencargan derealizar la instrucción de realizar la instrucción de la causa.

1 Correa R., Marcial. Para conocer la Constitución de 1993. Biblioteca: “Lo que debo saber”. Vol. IV. Pontificia Universidad Católica del Perú. Fondo Editorial 2004. Segunda reimpresión. Lima, 2004.

2 Gómez Mendoza, G. Ley Orgánica del Poder Judicial. Editora Rodhas. Lima, 1994.

3 Justicia Viva. Manual del Sistema Peruano de Justicia. Instituto de Defensa Legal. PUCP. Facultad de Derecho, Jueces para la Justicia y Democracia. Lima, 2003.

4 Ley Orgánica del Poder Judicial. Art. 102

5 Constitución Política del Perú. Art. 141

6 Manual del Sistema Peruano de Justicia. Idem. P. 38

Ley Orgánica del Poder Judicial. Art. 65

Art. 1 dela Constitución de la N ación Argentina û Ediciones País 8va. Edición. Buenos Aires, 2002.

Constitución Nacional Art. 117

10 Constitución Nacional Art. 116

11 Información obtenida vía Internet

12 Información obtenida vía Internet

13 La Constitución de los Estados Unidos deA mérica. Con notas explicativas. Servicio Informativo y Cultural de los Estados Unidos. 1987.

${ }^{14}$ Constitución de Italia de 1947

15 Constitución de Italia de 1947 